\title{
Effects of Plasma Surface Treatment on Cell Adhesion to Biocompatible Polymer Brushes
}

\author{
Yasushi Sasai $^{1^{*}}$, Naoki Doi ${ }^{1}$, Yukinori Yamauchi ${ }^{2}$, \\ Masayuki Kuzuya ${ }^{3}$, and Shin-ichi Kondo ${ }^{1}$ \\ ${ }^{1}$ Laboratory of P harmaceutical Physical Chemistry, Gifu Pharmaceutical U niversity, \\ 1-25-4 Daigaku-Nishi, G ifu 501-1196, Japan \\ ${ }^{2}$ D epartment of Pharmaceutical Physical Chemistry, College of P harmaceutical Sciences, \\ M atsuyama U niversity, 4-2 Bunkyo-cho, M atsuyama, Ehime 790-8578, J apan \\ ${ }^{3}$ C hubu Gakuin U niversity, 2-1 Kirigaoka, Seki-shi, G ifu 501-3993, J apan \\ *sasai@gifu-pu.ac.jp
}

\begin{abstract}
Argon plasma-induced reactions on biocompatible methacrylic polymer brushes were investigated to evaluate the influence on the cell adhesion properties. Polymer brushes of poly(sulfobetaine methacrylate) (PSBMA) and poly(phosphobetaine methacrylate) (PPBMA) were prepared on various substrates using surface-initiated atom transfer radical polymerization techniques. The degradation of PSBMA brushes by Ar plasma irradiation was suppressed than that of PPBMA brushes. This might result from interchain and intrachain interactions of sulfobetaine moieties in PSBMA brushes. Moreover, cell adhesion on plasma-irradiated PSBMA brushes were significantly improved as compared with that to a commercial tissue culture polystyrene dish, suggesting that the resultant surfaces can be used as good scaffolds for cell adhesion.

Keywords: Plasma surface treatment, Cell adhesion, Polymer brushes, Zwitterionic polymethacrylates
\end{abstract}

\section{Introduction}

Plasma surface treatment is a versatile method to create functional surfaces of various polymeric materials [1-3]. It is well known that the surface reactions caused by plasma treatment are initiated by plasma-induced radicals. Thus, we have undertaken plasma-irradiation to a wide variety of synthetic and natural polymers. The surface radicals so formed were studied in detail by electron spin resonance (ESR) coupled with the aid of systematic computer simulations [4-9]. The findings obtained from these series of studies were used to open up various plasma-assisted application works [10-12].

Densely grafted thin polymer layers are called "polymer brushes". These are constructed on material surfaces and are effective for altering surface properties and widely used in biomedical fields for surface functionalization of materials to obtain blood compatible materials, lubricant surfaces, functional substrate/cell interfaces, and biosensing platforms with resistance against non-specific adsorption from biological samples [13-15]. In particular, polymer brushes of betaine type zwitterionic polymers, such as poly(sulfobetaine methacrylate) (PSBMA) and poly(phosphobetaine methacrylate) (PPBMA) (Fig. 1), have been recognized as promising biocompatible materials for biomedical applications due to the excellent antifouling properties [16,17]. Additionally, plasma and UV irradiation techniques have been applied to polymer brushes prepared on solid substrates to construct patterned surfaces and introduce functional groups for further applications [18-22]. In order to closely monitor the effects of post modification of polymer brushes by plasma surface treatment, in this study, we examined plasma-induced reactions on zwitterionic polymer brushes. Moreover, effects of plasma surface treatment on cell adhesion to the polymer brushes were evaluated for cell culture applications. 


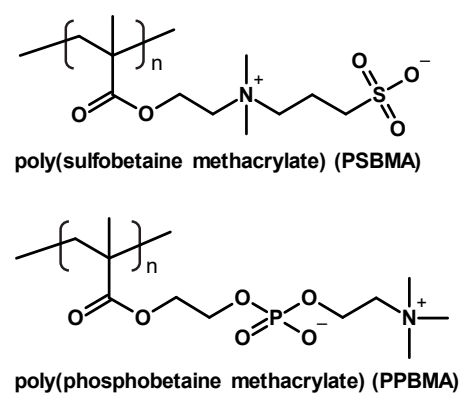

Fig. 1. Structures of PSBMA and PPBMA.

\section{Experimental}

\subsection{Materials}

Spherical silica particles (NP-200, average diameter $=20 \mu \mathrm{m})($ SiPs $)$ were kindly donated by AGC Si-Tech Co., Ltd. (2-Methacryloyloxy)ethyl dimethyl-(3-sulfopropyl) ammonium hydroxide, or sulfobetaine methacrylate (SBMA), was purchased from Chem-Impex Inc. and used as received. 2-Methacryloyloxyethyl phosphorylcholine, or phosphobetaine methacrylate (PBMA) were purchased from Sigma-Aldrich and used after removing inhibitor. 2-Bromoisobutyryl bromide (BIBB), $\mathrm{CuBr}, \mathrm{CuBr}_{2}, \quad 2,2$ '-bipyridyl (bpy), 3-aminopropyltriethoxysilane (APTES) were obtained from Sigma-Aldrich and were used as received.

\subsection{Analytical methods}

Electron spin resonance (ESR) spectra of plasma irradiated polymer brush-modified SiPs samples were obtained on an X-band ESR spectrometer (JES FA-200, JEOL) at room temperature. X-ray photoelectron spectroscopy (XPS) measurements were performed to determine surface chemical compositions of polymer brushes using a PHI Quantera SXM instrument (ULVAC-PHI) with $\mathrm{AlK} \alpha$ as the X-ray radiation source operated at 10 $\mathrm{mA}$ and $20 \mathrm{kV}$. Thermogravimetric analysis (TGA) was performed to determine the amount of polymer brushes prepared on SiPs using a TG/DTA6200 (Seiko Instrument) with heating rate of $10{ }^{\circ} \mathrm{C} / \mathrm{min}$ under $\mathrm{N}_{2}$ flow.

\subsection{Synthesis of polymer brushes on SiPs}

The ATRP initiator, 3-(2-bromoisobutyramido)propyltriethoxysilane (BIBAPTES), was synthesized by the reaction of APTES with BIBB according to literature [23]. The SiPs surfaces were cleaned and activated by piranha solution $\left(\mathrm{H}_{2} \mathrm{SO}_{4}: \mathrm{H}_{2} \mathrm{O}_{2}=7: 3(\mathrm{v} / \mathrm{v})\right)$ for $1 \mathrm{~h}$ at $60{ }^{\circ} \mathrm{C}$. At the end of cleaning, acidic solution was removed by centrifugation. Then the SiPs were extensively rinsed with ultrapure water, ethanol and dry toluene. The surface activated SiPs were dispersed in dry toluene and then BIBAPTES was added via syringe to a concentration of $10 \mathrm{mM}$. After overnight stirring of the particles at room temperature, the solution was removed by centrifugation. After washing with toluene and ethanol, the BIBAPTES-modified SiPs thus prepared were dried in vacuum and then served for surface-initiated atom transfer radical polymerization (SI-ATRP) of methacrylate monomers. A solution consisting of [mononer] $/[\mathrm{CuBr}] /\left[\mathrm{CuBr}_{2}\right] /$ [bpy] feed ratio of $50(0.6 \mathrm{M}): 1: 0.2: 1.2$ in a mixture of water and methanol $(1: 1(\mathrm{v} / \mathrm{v})$ for SBMA and 1:4 (v/v) for PBMA) was added into a flask containing BIBAPTES-modified SiPs under a nitrogen atmosphere and stirred at room temperature for a prescribed period of time.

2.4. Synthesis of polymer brushes on polystyrene cell culture dish

Surface bromination of polystyrene (PS) dish was conducted by the method reported earlier [18]. The polymer brushes on PS dish were prepared by SI-ATRP of methacrylate monomers in a solution consisting of $[$ mononer $] /[\mathrm{CuBr}] /\left[\mathrm{CuBr}_{2}\right] /[\mathrm{bpy}]$ with a feed ratio of $100(1.0 \mathrm{M}): 1: 0.2: 1.2$ in $1 \mathrm{M}$ $\mathrm{NaCl}$ aqueous solution for SBMA and in a mixture of methanol and water $(1: 4(\mathrm{v} / \mathrm{v}))$ for PBMA from surface-brominated PS dishes.

\subsection{Plasma surface treatment}

The polymer brush-modified SiPs were placed on a glass ampule $(50 \mathrm{~mL})$ and the plasma state was generated by the use of radio-frequency discharge of inductive coupling at $13.56 \mathrm{MHz}$ with supplied power of $50 \mathrm{~W}$. Flow volume $(50$ $\mathrm{mL} / \mathrm{min}$ ) and pressure (66.6 Pa (0.5 Torr)) of argon gas were controlled by flow meter and evacuating speed. For flat substrate sample, polymer brush-modified PS dishes were placed in a reaction chamber (230 $\mathrm{mm}$ long, $45 \mathrm{~mm}$ in diameter) and the plasma was generated under same conditions with that for plasma irradiation to SiPs samples

\subsection{Cell adhesion test}

Human hepatocellular carcinoma cell line, HepG2, was used for cell adhesion test. HepG2 cells was routinely cultured in E-MEM supplemented with $2 \mathrm{mM}$ glutamine, $1 \%$ nonessential amino acids, $10 \%$ fetal bovine serum, 100 units $/ \mathrm{mL}$ penicillin and $100 \mu \mathrm{g} / \mathrm{mL}$ streptomycin at $37{ }^{\circ} \mathrm{C}$ under a humidified atmosphere of $5 \% \mathrm{CO}_{2}$. 
After trypsin treatment, the cell suspension of the prescribed concentration was prepared and was seeded into PS dish samples. At a given time, the number of cells adhered on each dish was determined using the cell proliferation reagent for WST-1 assay (Dojindo Laboratories).

\section{Results and discussion}

3.1. Plasma surface treatment of polymer brushes

The effects of plasma surface treatment of polymeric materials were assessed by observing the plasma-induced radicals. Radicals observed on polymer brushes prepared on SiPs (brush thickness $=\sim 130 \mathrm{~nm}$ for PPBMA and $\sim 160 \mathrm{~nm}$ for PSBMA) after Ar plasma irradiation for $60 \mathrm{~s}$ were measured by ESR spectroscopy. As can be seen in Fig. 2, ESR spectra with similar features were observed in both polymer brushes and those were essentially identical with those of plasma-induced radicals obtained from methacrylic polymers reported previously, indicating that tertiary end-chain radicals were mainly formed in PPBMA and PSBMA [5]. Figure 3 shows the progressive changes in ESR spectral intensity (A) and weight of polymer brush-modified SiPs (B) on plasma duration. While similar kinetics of radical generation for short plasma duration $(<60 \mathrm{~s})$ were observed in both polymer brushes, the radical concentration in PPBMA brushes was found to level off earlier than PSBMA and the rate of degradation of PPBMA was much higher than PSBMA. These results suggest the difference of degradation properties by plasma irradiation between PSBMA and PPBMA brushes.

To gain more insight of plasma-induced reaction on both polymer brushes, effects of plasma irradiation on the chemical structures of polymer brushes prepared on PS dishes were evaluated by XPS (Fig. 4). The XPS $C_{1 s}$ spectra obtained from

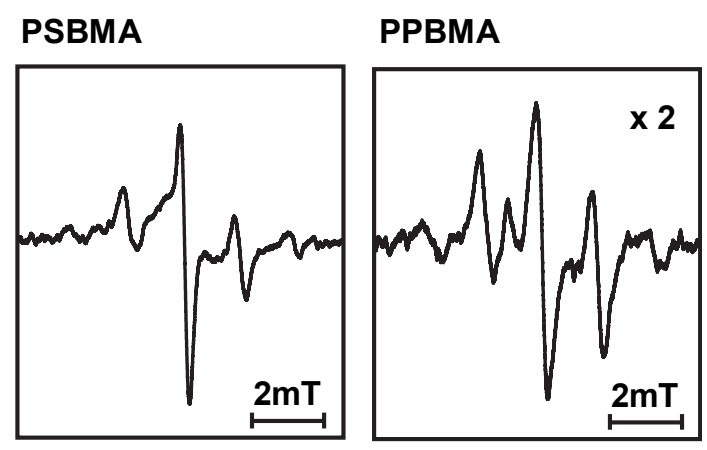

Fig. 2. Observed ESR spectra of PSBMA and PPBMA brushes after plasma irradiation for $60 \mathrm{~s}$.
PSBMA brushes were almost same pattern before and after plasma irradiation for $60 \mathrm{~s}$. In PPBMA brushes, on the other hand, the relative signal intensity corresponding to $\underline{\mathrm{C}}(=\mathrm{O})-\mathrm{O}(\mathrm{ca} .289 .0 \mathrm{eV})$, and $\mathrm{C}-\mathrm{O}, \underline{\mathrm{C}}-\mathrm{N}$ (ca. $286.5 \mathrm{eV}$ ) significantly decreased by plasma irradiation. We also evaluated the changes in film thickness of PSBMA and PPBMA brushes prepared on silicon wafer by Ar plasma irradiation. The brush thickness for PSBMA and PPBMA decreased from $\sim 88 \mathrm{~nm}$ to

(A)

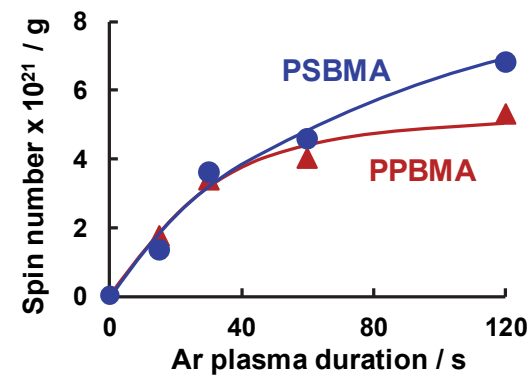

(B)

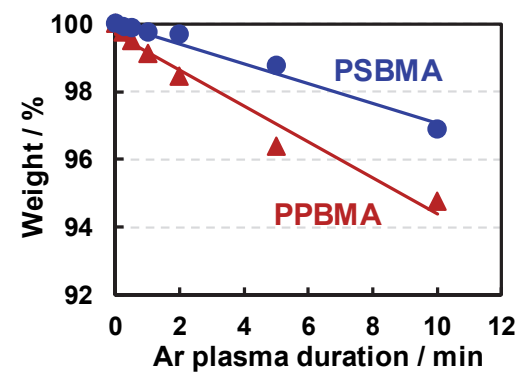

Fig. 3. (A) Progressive changes in radical concentration observed in polymer brush-modified SiPs on plasma duration and (B) kinetics of weigh loss of polymer brush-modified SiPs by plasma irradiation.

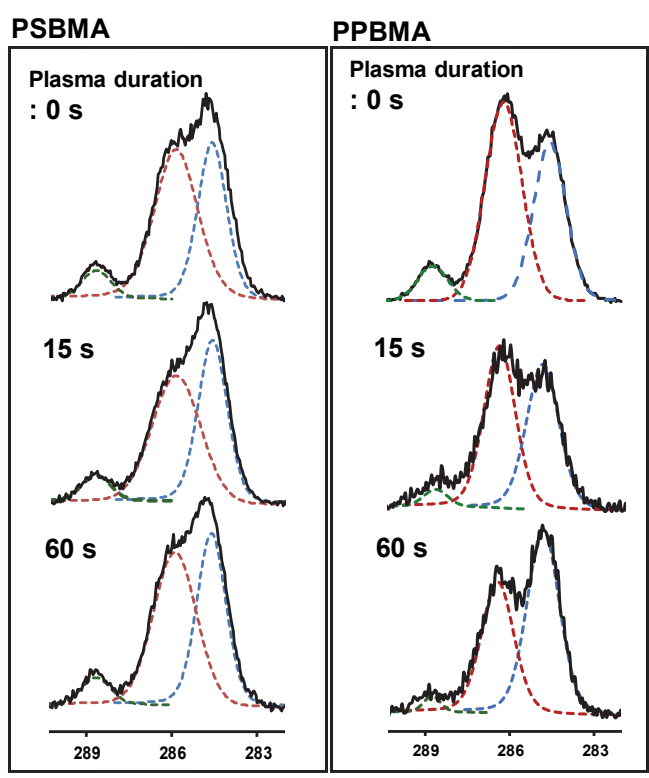

Fig. 4. XPS $\mathrm{C}_{1 \mathrm{~s}}$ spectra of polymer brushes prepared on PS dish before and after plasma irradiation. 
$\sim 81 \mathrm{~nm}$ and from $\sim 67 \mathrm{~nm}$ to $\sim 45 \mathrm{~nm}$ by plasma irradiation for $30 \mathrm{~s}$, respectively. These results suggest that ester groups of PPBMA were easily decomposed by plasma irradiation. It has been known that decarboxylation and deesterification of acrylic and methacrylic polymers are easily caused by plasma irradiation. Moreover, the resultant mid-chain radicals in methacrylate polymers involve depolymerization of the polymer main-chain by $\beta$-scission. [5] Therefore, degradation properties of PSBMA shown in Figs. $3 \mathrm{~B}$ and 4 mean that the initial elimination of ester groups in PSBMA brushes by plasma irradiation is somewhat suppressed. Hucks et al. reported the strong interchain association between zwitterionic sidechains in high-density PSBMA brushes [24]. Such interactions might result in suppression of plasma-induced deesterification of PSBMA in the brushes.

\subsection{Cell adhesion properties}

The effects of plasma irradiation on cell adhesion to PSBMA and PPBMA brushes were examined. The numbers of HepG2 cells adhered to plasma-irradiated polymer brushes for various durations were evaluated by WST-1 assay after 1 day-cell culture. For comparison purposes, cell adhesion on a commercial Tissue Culture Polystyrene (TCPS) dish was also tested in the same manner. Figure 5 summarizes the result as relative values. No adhered cells were observed on PSBMA and PPBMA brushes due to the excellent antifouling properties of both polymer brushes. Interestingly, the number of adhered cells on PSBMA brushes which were plasma-irradiated for

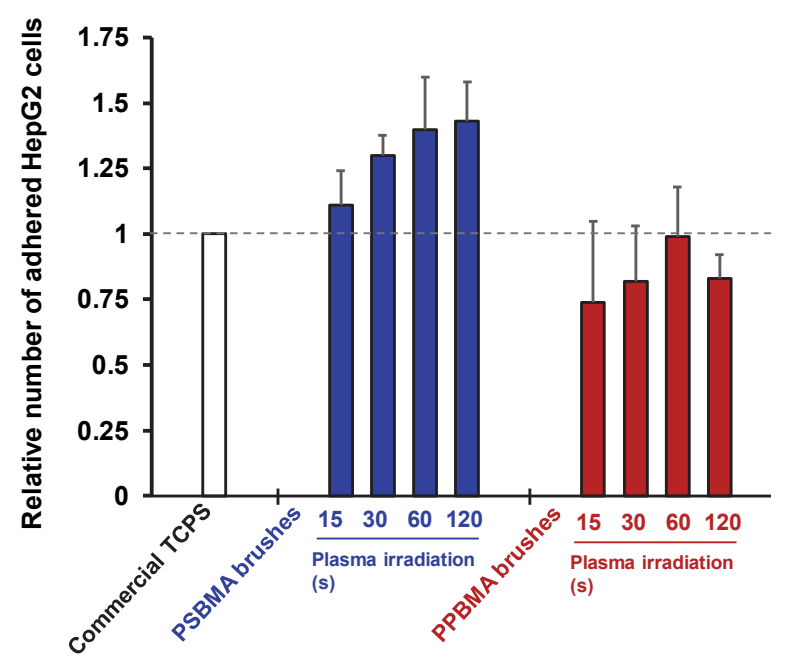

Fig. 5. Effects of plasma irradiation on cell adhesion to PSBMA and PPBMA brushes. over $15 \mathrm{~s}$ was larger than that on TCPS and increased with plasma duration. On the other hand, although cell adhesion to PPBMA brushes occurred even after short plasma irradiation, the surface did not work as more favorable scaffold for cell adhesion than TCPS and plasma-irradiated PSBMA brush surfaces. Considering that cell adhesion was usually mediated by adsorption of proteins in cell culture medium onto substrates, results shown in Fig. 5 can be explained by the difference of protein adsorption properties between PSBMA and PPBMA brush surfaces after plasma irradiation because surface chemistry was quite difference as shown in Fig. 4. We also need to evaluate effects of plasma-induced changes in surface morphology in terms of surface roughness and thickness of PSBMA brushes on cell adhesion.

\section{Conclusion}

In this study, we investigated the effects of $\mathrm{Ar}$ plasma irradiation on cell adhesion to two biocompatible zwitterionic methacrylate polymer brushes- PSBMA and PPBMA. The results indicated that surface reactions caused by argon plasma irradiation were different between both polymer brushes and plasma-induced degradation was suppressed in PSBMA brushes. Interestingly, plasma-irradiated PSBMA brushes work as an effective scaffold for adhesion of HepG2 cells. The results obtained from this study can be useful for preparing functional substrates for patterned cell culture and promoting cell adhesion and proliferation.

\section{Acknowledgement}

This work was supported by Japan Society for the Promotion of Science (JSPS) KAKENHI (Grant No. 15K07893).

\section{References}

1. T. Desmet, R. Morent, N. De Geyter, C. Leys, E. Schacht, and P. Dubruel, Biomacromolesules, 10 (2009) 2351.

2. K. Bazaka, M. V. Jacob, R. J. Crawford, and E. P. Ivanova, Acta Biomater., 7 (2011) 2015.

3. J. M. Grace and L. J. Gerenser, J. Disper. Sci. Technol., 24 (2003) 305.

4. M. Kuzuya, A. Noguchi, H. Ito, S. Kondo, and N. Noda, J. Polym. Sci. A: Polym. Chem., 29 (1991) 1.

5. M. Kuzuya, A. Noguchi, M. Ishikawa, A. Koide, K. Sawada, A. Ito, and N. Noda, J . P hys. Chem., 95 (1991) 2398. 
6. M. Kuzuya, H. Ito, S. Kondo, N. Noda, and A. Noguchi, M acromolecules, 24 (1991) 6612.

7. M. Kuzuya, J. Niwa, and H. Ito, Macromolecules, 26 (1993) 1990.

8. M. Kuzuya, K. Morisaki, J. Niwa, Y. Yamauchi, and K. Xu, J. Phys. Chem., 98 (1994) 11301.

9. M. Kuzuya, T. Yamashiro, S. Kondo, M. Sugito, and M. Mouri, Macromolecules, 31 (1998) 3225.

10. M. Kuzuya, S. Kondo, and Y. Sasai, Plasmas Polym., 6 (2001) 145.

11. M. Kuzuya, S. Kondo, and Y. Sasai, Pure Appl. Chem., 77 (2005) 667.

12. M. Kuzuya, Y. Sasai, Y. Yamauchi, and S. Kondo, J. P hotopolym. Sci. Technol., 21 (2008) 785.

13. M. Krishnamoorthy, S. Hakobyan, M. Ramstedt, and J. E. Gautrot, Chem. Rev., 114 (2014) 10976.

14. W. L. Chen, R. Cordero, H. Tran, and C. K. Ober, Macromolecules, 50 (2017) 4089.

15. J. O. Zoppe, N. C. Ataman, P. Mocny, J. Wang, J. Moraes, and H.-A. Klok, Chem. Rev., 117 (2017) 1105.
16. Y. Higaki, M. Kobayashi, D. Murakami, and A. Takahara, Polym. J ., 48 (2016) 325.

17. M. He, K. Gao, L. Zhou, Z. Jiao, M. Wu, J. Cao, X. You, Z. Cai, Y. Su, and Z. Jiang, Acta Biomater., 40 (2016) 142.

18. Y. Sasai, A. Komatsu, S. Kondo, Y. Yamauchi, and M. Kuzuya, J. Photopolym. Sci. Technol., 27 (2014) 369.

19. A. Tourovskaia, T. Barber, B. T. Wickes, D. Hirdes, B. Grin, D. G. Castner, K. E. Healy, and A. Folch, Langmuir, 19 (2003) 4754.

20. S. A. Ahmad, A. Hucknall, A. Chilkoti, and G. J. Leggett, Langmuir, 26 (2010) 9937.

21. A. M. Alswieleh, N. Cheng, I. Canton, B. Ustbas, X. Xue, V. Ladmiral, S. Xia, R. E. Ducker, O. E. Zubir, M. L. Cartron, C. N. Hunter, G. J. Leggett, and S. P. Armes, J. Am. Chem. Soc., 136 (2014) 9404.

22. K. Mandal, M. Balland, and L. Bureau, PLOS One, 7 (2012) e37548.

23. G. Panzarasa, G. Soliveri, K. Sparnacci, and S. Ardizzone, Chem. Commun., 51 (2015) 7313.

24. N. Cheng, A. A. Brown, O. Azzaroni, and W. T. S. Huck, M acromolecules, 41 (2008) 6317. 